\title{
Appraisal of eco friendly products developed by natural fabric printed with natural dyes and natural thickener
}

\author{
SUDHA BABEL AND LATIKA SACHIHAR
}

Received: 09.01.2017; Revised: 03.04.2017; Accepted: 20.04.2017

See end of the paper for authors' affiliations SUDHA BABEL

Department of Textiles and Apparel Designing, College of Home Science, Maharana Pratap University of Agriculture and Technology, UDAIPUR (RAJASTHAN) INDIA
ABSTRACT : Natural dyes and natural thickening agents appear to be ideal choice. This is because natural dyes and thickening agents have better biodegradability and higher compatibility with environment. The block and screen printed silk and cotton fabric using indigo dye with starch extracted from Mango kernel seed has been carried out. To explore the acceptability of Eco friendly printed products, for this purpose Block and screen printed products like stole, table cover, bed sheet, scarf, duppatta, Saree border, necktie, magazine holder and letter holder were hand printed using natural starch obtained by Mango kernel and natural dye concentrate. Opinion of thirty respondents was obtained. Results revealed that all the printed products were liked by all the respondents. All the respondents were willing to purchase the products.

KEY WORDS: Natural fabric, Natural printing, Natural thickening agent, Eco friendly product, Acceptability of natural printed products

- HOW TO CITE THIS PAPER : Babel, Sudha and Sachihar, Latika (2017). Appraisal of eco friendly products developed by natural fabric printed with natural dyes and natural thickener. Asian J. Home Sci., 12 (1) : 104-108, DOI: 10.15740/HAS/AJHS/12.1/104-108. 